\title{
ANTIFIBROTIC ACTIVITY OF MESNA AGAINST AMIODARONE-ASSOCIATED LUNG INJURY IN WISTAR RATS
}

\author{
BAHIR ABDUL RAZZAQ MSHIMESH* \\ Department of Pharmacology and Toxicology, College of Pharmacy, Mustansiriyah University, Baghdad, Iraq. \\ Email: dr.bahirrazzq@uomustansiriyah.edu.iq
}

Received: 22 October 2018, Revised and Accepted: 08 December 2018

\begin{abstract}
Objective: Lung fibrosis is a progressive respiratory disease with a high percentage of mortality. Till now, it had bad prognosis to conventional medications. This study was designed to evaluate the role of mesna, the well-known antioxidant agent, against pulmonary fibrosis

Methods: Pulmonary fibrosis was induced by administration of amiodarone to Wistar rats. Lung indices, leukocytes count, oxidative stress markers, cytokines levels, and hydroxyproline contents, in addition to the histopathological tests, were done for control, amiodarone, and mesna plus amiodarone group.

Results: The elevated ratio of lung/body weight and total leukocytes count within bronchoalveolar lavage fluid for amiodarone rats was decline significantly when cotreated with mesna therapy. Furthermore, mesna significantly brought down the lipid peroxidation of amiodarone in lung tissue, represented by decreasing malondialdehyde level and increasing superoxide dismutase (SOD) and catalase activity. In addition, mesna diminished the profibrotic transforming growth factor- $\beta 1$ level while elevated the antifibrotic interferon- $\gamma$ level, and the high activity of the enzyme matrix metalloproteinase-7 was restored within mesna group. Meanwhile, mesna counteracts the increment of hydroxyproline contents and Ashcroft grading scale within amiodarone group. Histologically, critical improvement in the inflammatory cell penetration and alveolar septa was seen in the lung tissue of rats within mesna group, contrasted with those received just amiodarone. Trichome staining clarified that collagen deposition was notably diminished in the peri-alveolar and peri-bronchial area within mesna group. Moreover, mesna therapy downregulated SMAD3 protein level, which was overexpressed by amiodarone challenge.
\end{abstract}

Conclusion: This study gives evidence that mesna therapy may act as a protective agent against amiodarone-mediated pulmonary fibrosis.

Keywords: Pulmonary fibrosis, Amiodarone, Mesna.

(c) 2019 The Authors. Published by Innovare Academic Sciences Pvt Ltd. This is an open access article under the CC BY license (http://creativecommons. org/licenses/by/4. 0/) DOI: http://dx.doi.org/10.22159/ajpcr.2019.v12i1.30368

\section{INTRODUCTION}

Pulmonary fibrosis is a disorder set apart by scarring in the lungs. Tissue somewhere down in the lungs turns out to be thick, hardened, and scarred, due to the aggregation of abundance connective tissue that is named "fibrosis." As the lung tissue ends up scarred and thickening of its contents, oxygen supply in circulation diminished, which change a man's capacity to inhale [1]. This disease is the most widely recognized of interstitial pulmonary disorders, and influences $<5$ million individuals in the world, with a mean survival rate of about 3 years. Despite the fact that exploration studies are continuous, there is no confirmation that any solution can altogether help with this disorder [2]

Management with amiodarone, a broad-spectrum antiarrhythmic drug, is related to lung damage bringing about deadly respiratory fibrosis [3]. The pathogenesis for amiodarone lung damage incorporates a direct injury to pulmonary tissue, extreme sensitivity response, lipid peroxidation, change of cell membrane features and stimulation of alveolar macrophages, ending with cytokine discharge, and release of other inflammatory mediators [4]. In spite of much data with respect to the component of amiodarone-initiated pulmonary fibrosis, treating this disease is much of the time troublesome, and measurement protocols to deal with stopping its progression still scanty [5].

Sodium 2-mercaptoethane sulfonate (mesna) is utilized medically to protect against hemorrhagic cystitis caused by chemotherapeutic agents such as ifosfamide and cyclophosphamide [6]. Mesna is a compound with small size and by uprightness of its sulfhydryl moiety, can possibly capturing the free radicals. At the point when given IV, mesna is metabolized in the circulation to its inert disulfide compound "demensia" which enter renal tubules and return back to its source "mesna" by glutathione (GSH) [7]. Due to the small mesna size, its capacity to take up by various tissues, and its free radical scavenging potential, it might be valuable for limiting tissue insult caused by different oxidant species [8].

Whereas many antioxidant agents had failed to ameliorated lung damage initiated by amiodarone therapy in animal models, the role of mesna in counteracting this insult has not yet been tested. This study was formed to detect the possible protective activity of mesna against lung fibrosis induced by amiodarone in Wistar rats.

\section{METHODS}

\section{Experimental protocol}

This research included 30 Wistar albino male rats weighing (180-220 g); they were gotten from the animal house, and the work was permitted by the ethics committee for animal experimentation in the College of Pharmacy/Mustansiriya University. The animals were kept up at controlled temperature $\left(25 \pm 2^{\circ} \mathrm{C}\right)$ with light timetable $12-12 \mathrm{~h}$ light/dim cycles, enabled free access to water, and the nourished standard rodent chow included ad libitum. Mesna vial $(1 \mathrm{~g} / 10 \mathrm{ml})$ was acquired from Asta Pharma AG Germany, while amiodarone hydrochloride vial $(150 \mathrm{mg} / 3 \mathrm{ml})$ from Sigma Chemicals, St Louis, MO, USA. All other chemicals and kits were of the highest purity.

Rats were randomized into three groups, each comprising 10 animals, as follow: Group $1(\mathrm{n}=10)$ : On saline i.p for 3 weeks and considered 
as negative control group; Group 2 ( $\mathrm{n}=10)$ : $0 \mathrm{n}$ saline i.p for 1 week before and 2 weeks with amiodarone $(100 \mathrm{mg} / \mathrm{kg} / \mathrm{day}$ i.p $)$ and considered as positive control group; while Group $3(\mathrm{n}=10)$ : On mesna $(180 \mathrm{mg} / \mathrm{kg} /$ day, i.p.) for 1 week before and 2 weeks with amiodarone (100 mg/kg/day i.p) and considered as interventional treatment group.

Sampling of bronchoalveolar lavage (BAL)

Post-anesthesia, lung organs were set up for lavage by tubing the trachea with a limited needle joined by a syringe. This lavage was acquired by washing the chest 3 times with $3 \mathrm{ml}$ normal saline through tracheal intubation. Cell suspensions were collected by centrifugation with low velocity. The hemocytometer was used for total cell counts, while cytospin preparations were used for differential cell counts by calculating cells colored with Giemsa stain [9]. The remaining of BAL fluid was used for additional tests.

\section{Sampling of lung tissues}

Toward the finish of study, cervical dislocation was used to sacrifice the animals under light ether anesthesia, where their relative lung weights and whole body weights were estimated to get lung indices by the formula: (weight of the lung)/(weight of the rat) $\times 100$. The lung tissues were isolated into two sections; one section was submerged in $0.9 \%$ normal saline to get the lung tissue homogenate which was set up in fitting homogenizing buffer solution and put away at $-80^{\circ} \mathrm{C}$ as aliquots for additional tests. The remaining section was submerged in formalin solution $(10 \%)$ for histopathological evaluation.

\section{Biochemical measures in lung tissues and BAL fluid}

Malondialdehyde (MDA) content was measured utilizing the thiobarbituric basic analysis as depicted by Ohkawa et al. [10], the level of superoxide dismutase (SOD) was estimated following the procedure of Kakkar et al. [11], while catalase level was surveyed by the technique for luck [12], where the breakdown of hydrogen peroxide is estimated. All these markers were detected in lung tissues.

Sandwich enzyme immunoassay (ELISA) technique was utilized for the measurement of interleukin-1 $\beta$ (IL-1 $1 \beta$ ) as indicated by the directions given with Ray Biotech. [13]. Examinations of interferon- $\gamma$ (IFN- $\gamma$ ) and transforming growth factor- $\beta 1$ (TGF- $\beta 1$ ) levels were additionally done with ELISA method using commercially available kits $[14,15]$. Rat IFN- $\gamma$ kit (Bender Med Systems, Austria) and Invitrogen Multispecies TGF- $\beta 1$ kit (BioSource, Invitrogen, USA) were utilized for assurance of these parameters. Matrix metalloproteinase-7 (MMP-7) levels were also estimated utilizing an ELISA kit (R and D Systems, Minneapolis, MN, USA) [16]. All these biomarkers were measured in BAL fluid.

Hydroxyproline contents of lung tissues were detected utilizing the Woessner's principle which depends on spectrophotometric technique [17]. The tissue tests taken for hydroxyproline assurance were rinsed with saline and dried in a broiler set for $72 \mathrm{~h}$ at $100^{\circ} \mathrm{C}$
Histological examination and masson's trichrome staining

After killing the rats, lung tissue was carefully dissected and fixed in $10 \%(\mathrm{w} / \mathrm{v})$ formaldehyde-phosphate buffered saline-buffered solution at $25^{\circ} \mathrm{C}$, got dried out utilizing different ethanol concentrations and inserted in paraffin. The paraffin-installed tissues were sliced to $5 \mu \mathrm{m}$ layers with a microtome (RM-2135, Leica Microsystems, Bensheim, Germany). To assess the histopathological alterations, the tissues were passing through hematoxylin and eosin staining, while to distinguish the extent of the collected collagen, staining was achieved with Masson's trichrome method [18] by a professional pathologist.

\section{Lung fibrosis grading}

Each section was separately surveyed for the extent of interstitial fibrosis utilizing the semi-quantitative evaluating system depicted by Ashcroft et al. 1988 [19]. A score graduated from 0 (healthy tissues) to 8 (complete fibrosis) depended. Fibrosis score of these areas was calculated based on the mean score of all fields.

\section{Immunohistochemical (IHC) assay}

Tissue sections from every rat were inserted in paraffin. Paraffin sections with $5 \mu \mathrm{m}$-thick were collected for microscope examination. The tissues were blocked to be incubated with rat's anti-SMAD3 antibodies, biotinylated, and streptomycin-marked goat anti-rat antibody (Wuhan, China) to detect SMAD3 expression according to staining intensity [20].

\section{Statistical analysis}

The results of this study were displayed as means \pm standard error of mean. Statistical evaluation was performed by analysis of variance and post hoc test. Chi-square test was utilized for comparison of fractions. All examinations were made utilizing the SPSS program and $\mathrm{p}<0.05$ was regarded as a significant difference.

\section{RESULTS}

Effects of mesna on body weight and relative lung weight

Compared to the control group, a significant decrease in the body weight was seen in the animals treated with amiodarone alone $(p<0.05)$. Mesna expanded the body weight in rats on amiodarone, yet no significant difference was observed compared with amiodarone group. Meanwhile, the elevated ratio of lung weight/body weight (lung indices) for the amiodarone group significantly declined when treated with mesna $(\mathrm{p}<0.05)$ (Table 1$)$.

\section{Effects of mesna on BAL differential and total leukocytes count} In general, the recovered fraction of BAL fluid did not differ significantly among all studied groups ( $>85 \%)$. Table 2 showed that, when contrasted with control rats, amiodarone induced a significant increment in the BAL total leukocytes count $(\mathrm{p}<0.05)$. Regarding rats receiving mesna, total white blood cell count was an approach to that of control. Meanwhile, neutrophils within differential cells count were markedly

Table 1: Effects of mesna on body weight and relative lung weight

\begin{tabular}{llllll}
\hline Group & $\mathbf{n}$ & Initial body weight $\mathbf{( g )}$ & Final body weight $\mathbf{( g )}$ & Lung weight (mg) & Lung indices (mg/kg) \\
\hline Control & 10 & $207.8 \pm 6.7$ & $305.8 \pm 16.2$ & $1,395.7 \pm 128.8$ & $4,567.4 \pm 258.4$ \\
Amiodarone & 10 & $207.0 \pm 8.8$ & $284.7 \pm 14.5^{*}$ & $2,192.0 \pm 335.3^{*}$ & $7,715.3 \pm 1,105.0^{*}$ \\
Amiodarone+Mesna & 10 & $207.9 \pm 8.6$ & $291.6 \pm 18.4$ & $1,931.0 \pm 201.2^{*} \#$ & $6,635.6 \pm 403.5^{*} \#$ \\
\hline
\end{tabular}

Values are expressed as mean \pm SEM. $n=$ No. of rats per group. ${ }^{*} \mathrm{p}<0.05$ versus control group, $\# \mathrm{p}<0.05$ versus amiodarone group

Table 2: Effects of mesna on BAL differential and total leukocytes count

\begin{tabular}{lllllll}
\hline Group & $\mathbf{n}$ & Total cells $\left(\times \mathbf{1 0}^{\mathbf{6}} \mathbf{~ m l}^{-\mathbf{1}}\right)$ & Macrophage (\%) & Lymphocytes (\%) & Neutrophils (\%) & Eosinophil (\%) \\
\hline Control & 10 & $0.55 \pm 0.056$ & $93.55 \pm 1.2$ & $3.9 \pm 1.7$ & $3.8 \pm 0.7$ & $1.3 \pm 0.1$ \\
Amiodarone & 10 & $1.17 \pm 0.083^{*}$ & $62.7 \pm 9.7^{*}$ & $11.3 \pm 1.3^{*}$ & $23.6 \pm 8.5^{*}$ & $2.2 \pm 1.4$ \\
Amiodarone+Mesna & 10 & $0.68 \pm 0.160$ & $86.4 \pm 5.4$ & $13.1 \pm 1.5 \#$ & $1.9 \pm 0.8$ & $0.5 \pm 0.6$ \\
\hline
\end{tabular}

Data presented as mean \pm SEM. BAL: Bronchoalveolar lavage, $\mathrm{n}$ : No. of rats per group. ${ }^{*} \mathrm{p}<0.05$ versus other groups, $\# \mathrm{p}<0.05$ versus control group 
elevated in BAL fluid of those within the amiodarone group $(\mathrm{p}<0.05)$ and this increment was significantly counteracted by mesna $(\mathrm{p}<0.05)$

\section{Effects of mesna on oxidative stress markers of lung tissue} Lipid peroxidation

The consequence of this research demonstrated an elevation in the level of MDA in rats given amiodarone alone over that of control, which could be a sign of amiodarone- mediated tissue damage and harm $(\mathrm{p}<0.05)$. Meanwhile, mesna therapy significantly brought down the lipid peroxidation of amiodarone in lung tissues $(\mathrm{p}<0.05)$ by approaching the typical MDA concentration within the control group (Table 3).

\section{SOD activity}

The levels of SOD in the lung tissues of rats on just amiodarone shown to be decline significantly in contrast to the control rats $(\mathrm{p}<0.05)$. Administration of mesna observed to be fruitful in reestablishing the levels of this enzyme (Table 3).

\section{Catalase activity}

The activity of catalase in the tissue homogenate of amiodarone group was shown significantly lower than that of control $(\mathrm{p}<0.05)$. Mesna treatment, which enhanced catalase action of rats, exhibited an approximate enzyme activity with that of control (Table 3).

\section{Effects of mesna on cytokines and MMP-7 levels of BAL fluid}

Table 4 clarified that a significant increment in IL-1 $\beta$ level was observed in rats received amiodarone when contrasted with those got just saline $(\mathrm{p}<0.05)$. However, those rats took mesna plus amiodarone showed no significant diminishing in IL-1 $\beta$ levels when contrasted with rats on amiodarone ( $p>0.05)$. Anyway, IL-1 $\beta$ levels in mesna rats exhibit a larger extent when contrasted with control, as shown in Table 4 $(\mathrm{p}<0.05)$.

As a profibrotic cytokine in BAL fluid, the TGF- $\beta 1$ level was markedly elevated in the amiodarone group than control $(\mathrm{p}<0.05)$. Furthermore, amiodarone essentially diminished the BAL levels of the antifibrotic cytokine "IFN $-\gamma$ " in contrast with the control rats $(\mathrm{p}<0.05)$ (Table 4). A significant decrement in TGF- $\beta 1$ levels and increment in IFN- $\gamma$ levels were detected for rats received mesna, in opposite to those on just amiodarone. In spite of these findings, a large difference continued in TGF- $\beta 1$ and IFN- $\gamma$ levels between rats taking mesna and those in the control group $(\mathrm{p}<0.05)$
Outcomes also demonstrated a noteworthy increment in the levels of MMP-7 in BAL fluid on the light of amiodarone challenge $(\mathrm{p}<0.05)$. The level of this enzyme in rats that got mesna therapy was observed to be uniquely lower than rats on just amiodarone $(\mathrm{p}<0.05)$ and in the meantime, was identical to that within the control ( $\mathrm{p}>0.05)$, as shown in Table 4.

\section{Assessment of lung fibrosis}

Pulmonary fibrosis was evaluated by estimating hydroxyproline amount as a marker of collagen deposition. Amiodarone created a marked increment in hydroxyproline contents when contrasted to the control $(\mathrm{p}<0.05)$. This augmentation was counteracted by mesna ( $p>0.05$ ) (Table 5). Meanwhile, Ashcroft scale was indicated for grading lung fibrosis. This semi-quantitative analysis was normal for control rats. Administration of amiodarone revealed 3-folds increment in the pathology score when contrasted with the control group $(\mathrm{p}<0.05)$. Mesna therapy significantly counteracts the expansion in the score, as shown in table 5 ( $p>0.05)$.

\section{Effects of mesna on the histological profile}

Animals within amiodarone group demonstrated particular histopathological changes, represented by alveolar structure damage, inter-alveolar septal thickening, and extensive interstitial invasion by neutrophils and lymphocytes (Fig. 1b) compared with control group (Fig. 1a). Interestingly, the mesna medications gave assurance against these amiodarone histological abnormalities. Critical improvement in the inflammatory process and alveolar septal architecture was seen within mesna-lung tissues, contrasted with rats received just amiodarone (Fig. 1c).
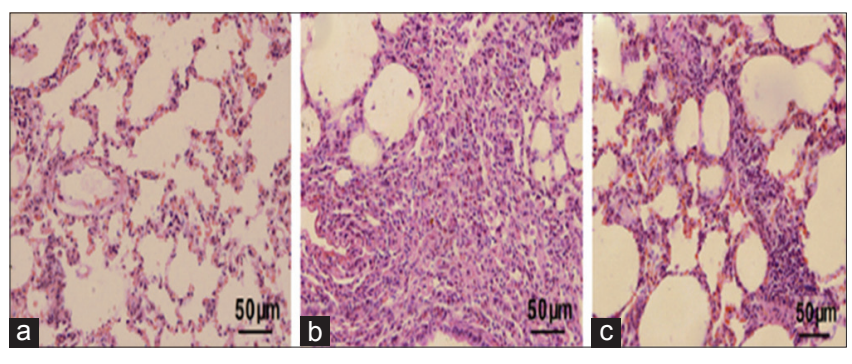

Fig. 1: Histological sections of lung tissues for the three studied groups. (a) Control group; (B) amiodarone group; and (C) amiodarone plus mesna group. Lung tissues were stained with $\mathrm{H}$ and $\mathrm{E}($ amplification $\times 400)$

Table 3: Effects of mesna on the levels of oxidative stress markers within lung tissue

\begin{tabular}{lllll}
\hline Group & $\mathbf{n}$ & MDA (nmoles/mg tissue) & SOD (U/mg tissue) & ${\text { CAT }\left(\mu \mathbf{m} \mathbf{H}_{2} \mathbf{O}_{2} \text { consumed/mg tissue/min) }\right.}^{\text {cons }}$ \\
\hline Control & 10 & $43.35 \pm 1.3$ & $0.33 \pm 0.05$ & $19.92 \pm 1.25$ \\
Amiodarone & 10 & $63.60 \pm 1.9^{*}$ & $0.20 \pm 0.02^{*}$ & $11.65 \pm 0.79^{*}$ \\
Amiodarone+Mesna & 10 & $45.59 \pm 1.2$ & $0.32 \pm 0.03$ & $18.36 \pm 1.50$ \\
\hline
\end{tabular}

Values are expressed as mean \pm SEM. MDA: Malondialdehyde, SOD: Superoxide dismutase, CAT: Catalase, n: No. of rats per group. ${ }^{*}$ p $<0.05$ versus other groups

Table 4: Effect of mesna on cytokines and MMP-7 levels of BAL fluid

\begin{tabular}{lllll}
\hline Group & $\mathbf{n}$ & $\mathbf{I L - 1} \boldsymbol{\beta}$ (pg/gm) & TGF- $\boldsymbol{\beta 1}$ (pg/ml) & IFN- $\boldsymbol{\gamma}$ (pg/ml) \\
\hline Control & 10 & $11.60 \pm 1.89$ & $50.18 \pm 25.90$ & $111.54 \pm 43.76$ \\
Amiodarone & 10 & $48.23 \pm 5.60^{*}$ & $261.57 \pm 70.66^{*}$ & $6.75 \pm 0.13$ \\
Amiodarone+Mesna & 10 & $38.54 \pm 4.11 \#$ & $142.37 \pm 8.25 \#$ & $11.60 \pm 0.65^{*}$ \\
\hline
\end{tabular}

Values are represented as mean \pm SEM. BAL: Bronchoalveolar lavage, IL-1 $\beta$ : Interleukin- $1 \beta$, TGF- $\beta 1$ : Transforming growth factor- $\beta 1$, IFN- $\gamma$ : Interferon- $\gamma$, MMP-7: Matrix metalloproteinase-7, n=No. of rats per group. ${ }^{*} \mathrm{p}<0.05$ versus other groups, $\# \mathrm{p}<0.05$ versus control group

Table 5: Hydroxyproline contents and grades of lung fibrosis

\begin{tabular}{llll}
\hline Group & $\mathbf{n}$ & Hydroxyproline (mg/g dried tissue) & Grade of fibrosis (Ashcroft score) \\
\hline Control & 10 & $8.25 \pm 0.60$ & $0.56 \pm 0.03$ \\
Amiodarone & 10 & $13.66 \pm 0.84^{*}$ & $1.62 \pm 0.15^{*}$ \\
Amiodarone+Mesna & 10 & $6.41 \pm 0.86$ & $0.52 \pm 0.06$ \\
\hline
\end{tabular}

Data presented as mean \pm SEM. $n=$ No. of rats per group. ${ }^{*} \mathrm{p}<0.05$ versus other groups 
Amount of collagen within the lungs considered as a marker of fibrosis after staining by Masson's trichrome method. Not surprisingly, rats administered amiodarone showed an expanding of collagen accumulation, compacted alveoli, and substantial fibrotic regions, contrasted with rats within the control group (Fig. 2a and 2b). Meanwhile, collagen deposition was notably diminished in lung tissues of mesna group (Fig. 2c) when contrasted with rats administered just amiodarone.

\section{Effects of mesna on SMAD3 expression within lung tissue}

Under IHC staining, SMAD3 expression was identified within alveolar macrophages. After receiving amiodarone, rats markedly overexpressed SMAD3 (Fig. 3b), contrasted with control rats which exhibited weaker staining intensity (Fig. 3a). Meanwhile, with mesna group, fewer positively cellular staining was seen (Fig. 3c).

\section{DISCUSSION}

In the current study, a notable decrease in the body weight was reported with rats on just amiodarone, which could be ascribed to the pulmonary fibrosis [21]. After amiodarone administration, a marked increment in the relative lung weight was seen, contrasted with control rats. One previous study has also revealed a comparable increment in lung weight of rats challenged with pulmonary fibrosis [22]. This expansion in lung weight is an unmistakable sign of fibrosis that is described by progressive collagen accumulation, as clear from the expanded quantity of hydroxyproline showed in the lungs of rats on just amiodarone. Meanwhile, mesna administration was seen adequately protect from the lung fibrosis induced by amiodarone, so relative lung weight and body weight of rats with mesna were approximate with that of control.

Interstitial inflammation might be associated with amiodarone therapy, this represented by an increase in the leukocytes count. It's revealed that the leukocytes assume a key part in the lung inflammatory process [23]. In the present study, a noteworthy increment in the total leukocytes count with a marked elevation in the lymphocytes, neutrophils, and eosinophils levels was apparent in the amiodarone group within BAL fluid. This finding was in accordance with previous reports studying drugs that initiate lung fibrosis [24,25]. The clear decline in the leukocytes level by mesna therapy shows considerable protection against lung inflammation caused by amiodarone, so documenting the

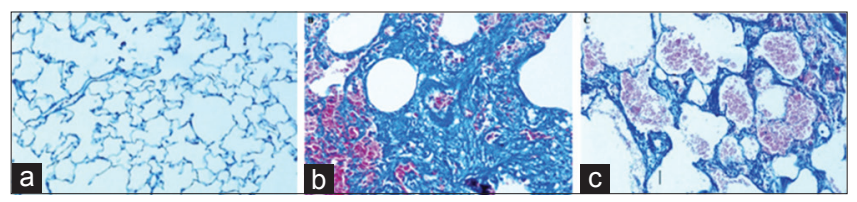

Fig. 2: Histological sections of lung tissues for the three studied groups. (a) Control group; (b) amiodarone group; and (c) amiodarone plus mesna group. Lung tissues were stained by Masson's trichrome method (amplification×200)

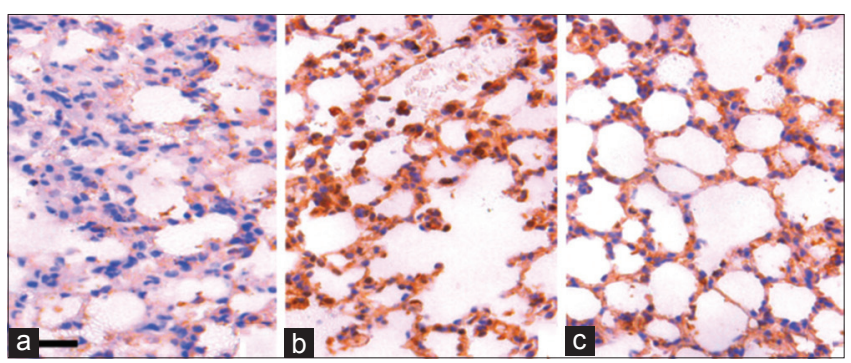

Fig. 3: Immunohistochemical staining for SMAD3 in lung tissues of the three studied groups. (a) Control group;

(b) amiodarone group; and (c) amiodarone plus mesna group (amplification $\times 200$ ) anti-inflammatory effect of this substance against lung damage induced by these chemicals.

During amiodarone administration, it's well documented that oxidative stress shared in the fibrotic accumulation within lung tissues. Once produced, reactive oxygen species (ROS) attacks specific targets such as DNA, lipid, protein, ending with cell membrane disruption, and lung injury [26]. In this study, we reported lipid peroxidation as represented by rising MDA activity within the amiodarone group. Furthermore, this group exhibited depletion in antioxidant activity, as evident by SOD and catalase levels reduction, in agreement with the findings of other studies $[27,28]$. However, it was observed that the extent of oxidative status approaches to that of control after administration of mesna, supporting its powerful antioxidant activities.

The process of oxidative stress may initiate lung injury that associated with amiodarone, which is upheld by the generation of superoxide anion through alveolar macrophages got from rats receiving amiodarone. Our results were in the line with that of Taylor et al., who revealed expanded oxidant generation in amiodarone group [29]. Along these lines, superoxide anion raised levels may reflect a respiratory reaction to an insult, and attenuating this oxidative stress by mesna could have restorative advantages for lung damage caused by amiodarone.

In a previous study, adding mesna to bleomycin inhibiting reduced GSH consumption and the subsequent lung harmful effects. The capacity of mesna to anticipate exhaustion of lung GSH pool proposed that its anti-fibrotic effect is attributed to its antioxidant activity. Mesna can spare GSH by going about as either stimulating its formation or by acting as ROS scavenger [30]. In accordance with our results, mesna had appeared to avoid damage after ischemia/reperfusion injury and its subsequent oxidative stress to renal tissue [6] and urotoxicity of ifosfamide [31], where it has been utilized as a valuable adjuvant to chemotherapeutic drugs.

Previous findings showed that activation of macrophages and release of inflammatory and cytotoxic mediators may drive amiodarone to induce lung fibrosis $[4,5]$. In the current study, the IL- $1 \beta$ level is elevated after receiving amiodarone, but not significantly reduced by mesna therapy. This pro-inflammatory cytokine is included in fibroblast deposition and acts potentially with TNF- $\alpha$ [32]. Hindrance of IL-1 $\beta$ was shown to inhibit pulmonary fibrosis attributed to bleomycin [33], while its upregulation initiates lung damage and fibrotic process in the late phases of the experimental models [34]. Furthermore, IL-1 $\beta$ and TNF- $\alpha$ can augment oxidant process in tissues [35], prompting generation of free radicals, which have been proposed to work as a cascade of signaling molecules [36]. In this manner, utilized of mesna in the present study, which associated with lowering the levels of these cytokines, was reported to inhibit oxidative stress.

Ongoing work exhibits that IL-1 $\beta$ initiates intense lung tissue infiltration ending with fibrosis, so it's viewed as a valid mediator for pharmacologic intervention in this disorder [37]. The TNF- $\alpha$ was appeared to fortify IL-1 $\beta$ release from macrophages, and, in turn, IL- $1 \beta$ upregulates TNF- $\alpha$ and IL-6, where IL- 6 additionally shown to be involved in the pathogenesis of lung fibrosis [38].

The TGF- $\beta 1$ and IFN- $\gamma$ are important players in the process of lung fibrosis. These mediators were utilized in numerous researches for fibrosis assessment [39]. In this study, an expansion was found in the levels of TGF- $\beta 1$ and a reduction in levels of IFN- $\gamma$ within amiodarone group; in accordance with the literature, while in mesna rats the creation of TGF- $\beta$ in the lungs was fundamentally diminished. The task of TGF- $\beta$ is basic in fibrosis as it converts fibroblast to myofibroblast and it's the most powerful stimulator of extracellular matrix generation. Upregulation of this profibrotic factor produces significant fibrosis [40]. Several studies demonstrated that hindrance of TGF- $\beta$ targeting molecule provides amelioration of the fibrotic process, 
recommending that medication focusing on the TGF- $\beta$ could offer a helpful pharmacologic intervention for this disease $[41,42]$.

IFN- $\gamma$ can inhibit repairing of wounds and has been reported to limit lung fibrosis initiated by bleomycin model, where its level is inadequate. It restricts the proliferation of fibroblasts and production of collagen by restraining TGF- $\beta$ upregulation [33]. Ziesche et al. demonstrated significant changes in the state of few subjects suffering fibrosis of lung tissues following IFN- $\gamma$ treatment and recommended that this impact was attributed to the restraint of TGF- $\beta 1$ [43]. In the current study, diminished levels of TGF- $\beta 1$ and expanded levels of IFN- $\gamma$ were seen in rats getting mesna versus those with just amiodarone.

Fibrosis can be defined as activation of extracellular matrix as a defense and repairing mechanism against tissue injury [44]. As has been accounted for by other studies, subjects with fibrosis of lung tissues demonstrate increased MMP-7 levels $[45,46]$. In addition, it has been found that rodents with MMP-7 knockout are shielded from drugs initiate lung damage, recommending the contribution of MMP-7 in the fibrotic process [47]. According to these observations, one can shed light on the possible role of this catalyst as a targeting enzyme of mesna. Without a doubt, our outcomes recommend a relationship of the MMP-7 level with lung fibrosis by amiodarone. This elevation was shown to be counteracted by mesna therapy. Whether mesna is straightly focusing MMP-7, however, it requires to be evaluated.

In this study, mesna ameliorated amiodarone-associated pulmonary fibrosis, as clarified by the noteworthy decrease in collagen deposition estimated as hydroxyproline level, a marker of collagen overproduction. Previous observations found that hydroxyproline elevation associated with amiodarone was reduced by the utilization of substances such as curcumin [48] and melatonin [49]. In addition, with the present study, mesna therapy also inhibits structural deformities mediated by amiodarone as represented by the reduction of Ashcroft score, contrasted with rats receiving amiodarone alone.

Evaluation of fibrosis through biochemical detection of hydroxyproline is more predictable strategy than Ashcroft grading for looking at the impacts of antifibrotic drugs. This may be attributed to the fact that Ashcroft method had a large fluctuation due to many variables. For example, bleomycin challenge can cause fibrotic patches in all scores, in this manner it is sensitized to errors, and ten-folds magnifying for microscopic testing may cause assessment errors due to the more prominent nonuniformity of fibrotic alterations within microscopic sections [50].

Histological investigations were achieved to verify abnormalities of lung tissue in the amiodarone group and to confirm the proposed antifibrotic activity of mesna against these alterations. We found that lung damage mediated by amiodarone involved dual phases: (a) Inflammatory represented by epithelial injury associated with infiltration of leukocytes and (b) fibroproliferative represented by fibrosis due to overactivation of the extracellular matrix. These results were in accordance with another previous report [51].

The current study confirms that mesna exhibits a powerful amelioration of pulmonary histopathological changes. These observations consisted with that of Daba et al. and Zhao et al. where different free radical scavengers were administered to counteract fibrosis associated with bleomycin [52,53]. Here, in spite that amiodarone and bleomycin are two different agents with distinct pharmacological action and indications, the pathogenesis of lung fibrosis induced by them is similar in many points.

Staining with Masson's trichrome additionally ensure fibrotic process mediated by amiodarone, which may be attributed to facilitating mobilization of collagen by collagenase enzyme "MMP-7." Histological evaluation by this method confirmed that amiodarone markedly obstructs alveolar spaces due to collagen deposition, in accordance with other reports [54,55]. Meanwhile, significant histological improvement with reduction of collagen accumulation was reported with rats given mesna therapy.

IHC, SMAD3 in the current study was upregulated in amiodarone group, while administration of mesna markedly decreased expression of this protein. This finding was consistent with the fact that SMAD proteins, a group of transcription factors, acting as signaling molecules within downstream pathway of TGF- $\beta 1$ receptors, where type I receptor stimulation leading to phosphorylation of SMAD2 and SMAD3 signaling pathway, ending with heteromerization with SMAD4 [56,57]. Deficiency of SMAD3 was also shown to ameliorate lung fibrosis mediated with bleomycin challenge in mice [58,59].

\section{CONCLUSION}

In this study, mesna seemed to have a protective role against amiodarone-mediated pulmonary fibrosis through inhibiting inflammatory status; augmenting antioxidant capacity; diminishing provocative cytokine levels; downregulating collagenase enzyme and preventing collagen deposition; and ending with improvement in the histologic morphology. In the future, mesna may be used clinically as an adjuvant agent with conventional therapy for this disorder. Further researches will be needed to know the mechanism of mesna in the pathogenesis of this disease.

\section{ACKNOWLEDGMENTS}

The author would like to thank Mustansiryiah University (www. uomustansiriyah.edu.iq), Baghdad, Iraq, for its support in the present work. Special thanks to the professional pathologist Dr. Basim for helping in animal dosing and histological work, and to the immunologist Dr. Suzan for supporting in laboratory tests and statistical analysis.

\section{AUTHORS' CONTRIBUTIONS}

Assistant Professor Dr. Bahir Abdul Razzaq (dr.bahirrazzq@ uomustansiriyah.edu.iq) has provided the design, protocol, and parameters suitable for conducting this experiment, in addition to the theoretical part (literature search, draft writing, and journal submission). Histological work (dissection, specimen collections, slide preparation, and reading) was achieved in a private laboratory.

\section{CONFLICTS OF INTEREST}

The author declared that there have no conflicts of interest.

\section{REFERENCES}

1. Kim DS. Acute exacerbations in patients with idiopathic pulmonary fibrosis. Respir Res 2013;14:86.

2. Maher TM. Idiopathic pulmonary fibrosis: Pathobiology of novel approaches to treatment. Clin Chest Med 2012;33:69-83.

3. Gill J, Heel RC, Fitton A. Amiodarone. An overview of its pharmacological properties, and review of its therapeutic use in cardiac arrhythmias. Drugs 1992;43:69-110.

4. Reinhart PG, Gairola CG. Amiodarone-induced pulmonary toxicity in Fischer rats: Release of tumor necrosis factor alpha and transforming growth factor beta by pulmonary alveolar macrophages. J Toxicol Environ Health 1997;52:353-65.

5. Chung WH, Bennett BM, Racz WJ, Brien JF, Massey TE. Induction of c-jun and TGF-beta 1 in Fischer 344 rats during amiodaroneinduced pulmonary fibrosis. Am J Physiol Lung Cell Mol Physiol 2001;281:L1180-8.

6. Mashiach E, Sela S, Weinstein T, Cohen HI, Shasha SM, Kristal B, et al. Mesna: A novel renoprotective antioxidant in ischaemic acute renal failure. Nephrol Dial Transplant 2001;16:542-51.

7. Gressier B, Lebegue N, Brunet C, Luyckx M, Dine T, Cazin M, et al. Scavenging of reactive oxygen species by letosteine, a molecule with two blocked-SH groups. Comparison with free-SH drugs. Pharm World Sci 1995; 17:76-80.

8. Gressier B, Cabanis A, Lebegue S, Brunet C, Dine T, Luyckx M, et al. Decrease of hypochlorous acid and hydroxyl radical generated by stimulated human neutrophils: Comparison in vitro of some thiol- 
containing drugs. Methods Find Exp Clin Pharmacol 1994;16:9-13.

9. Walters DM, Wills-Karp M, Mitzner W. Assessment of cellular profile and lung function with repeated bronchoalveolar lavage in individual mice. Physiol Genomics 2000;2:29-36.

10. Ohkawa H, Ohishi N, Yagi K. Assay for lipid peroxides in animal tissues by thiobarbituric acid reaction. Anal Biochem 1979;95:351-8.

11. Kakkar P, Das B, Viswanathan PN. A modified spectrophotometric assay of superoxide dismutase. Indian J Biochem Biophys 1984;21:130-2.

12. Luck H. A spectrophotometric method for the estimation of catalase. In: Bergmeyer HU, editor. Methods of Enzymatic Analysis. New York, USA: Academic Press; 1963. p. 886-7.

13. Grassi L, Roberge CJ, Frobert Y. Determination of IL- $\alpha$, IL- $\beta$, and IL-2 in biological media using specific enzyme immunometric assays. Immunol Rev 1991;119:125-42.

14. Schroder K, Hertzog PJ, Ravasi T, Hume DA. Interferon-gamma: An overview of signals, mechanisms and functions. J Leukoc Biol 2004; $75: 163-89$

15. Kim JS, Yoon SS, Kim YH, Ryu JS. Serial measurement of interleukin-6, transforming growth factor-beta, and S-100 protein in patients with acute stroke. Stroke 1996;27:1553-7.

16. Parks WC, Wilson CL, López-Boado YS. Matrix metalloproteinases as modulators of inflammation and innate immunity. Nat Rev Immunol 2004;4:617-29.

17. Edwards CA, O'Brien WD Jr. Modified assay for determination of hydroxyproline in a tissue hydrolyzate. Clin Chim Acta 1980;104:161-7.

18. Maynard JH. A trichrome stain in glycol methacrylate that works. Lab Med 1986;17:471.

19. Ashcroft T, Simpson JM, Timbrell V. Simple method of estimating severity of pulmonary fibrosis on a numerical scale. J Clin Pathol 1988;41:467-70.

20. Bonniaud P, Margetts PJ, Ask K, Flanders K, Gauldie J, Kolb M, et al. TGF-beta and SMAD3 signaling link inflammation to chronic fibrogenesis. J Immunol 2005; 175:5390-5.

21. Zhou XM, Zhang GC, Li JX, Hou J. Inhibitory effects of hu-qi-yin on the bleomycin-induced pulmonary fibrosis in rats. J Ethnopharmacol 2007;111:255-64.

22. Soumyakrishnan S, Sudhandiran G. Daidzein attenuates inflammation and exhibits antifibrotic effect against bleomycin-induced pulmonary fibrosis in Wistar rats. Biomed Prev Nutr 2011;1 Suppl 4:236-44.

23. Wei X, Han J, Chen ZZ, Qi BW, Wang GC, Ma YH, et al. A phosphoinositide 3-kinase-gamma inhibitor, AS605240 prevents bleomycin-induced pulmonary fibrosis in rats. Biochem Biophys Res Commun 2010;397:311-7.

24. Sriram N, Kalayarasan S, Sudhandiran G. Epigallocatechin-3-gallate augments antioxidant activities and inhibits inflammation during bleomycin-induced experimental pulmonary fibrosis through nrf2keap1 signaling. Pulm Pharmacol Ther 2009;22:221-36.

25. Gong LK, Li XH, Wang H, Zhang L, Chen FP, Cai Y, et al. Effect of feitai on bleomycin-induced pulmonary fibrosis in rats. J Ethnopharmacol 2005;96:537-44.

26. Liang X, Tian Q, Wei Z, Liu F, Chen J, Zhao Y, et al. Effect of feining on bleomycin-induced pulmonary injuries in rats. J Ethnopharmacol 2011;134:971-6.

27. Grande NR, Peao MN, DeSa CM, Aguas AP. Lung fibrosis induced by bleomycin: Structural changes and overview of recent advances. Scanning Microscope 1998;12:487-94.

28. Sogut S, Ozyurt H, Armutcu F, Kart L, Iraz M, Akyol O, et al. Erdosteine prevents bleomycin-induced pulmonary fibrosis in rats. Eur J Pharmacol 2004;494:213-20.

29. Taylor MD, Van Dyke K, Bowman LL, Miles PR, Hubbs AF, Mason RJ, et al. A characterization of amiodarone-induced pulmonary toxicity in F344 rats and identification of surfactant protein-D as a potential biomarker for the development of the toxicity. Toxicol Appl Pharmacol 2000;167:182-90.

30. Lord-Fontaine S, Averill DA. Enhancement of cytotoxicity of hydrogen peroxide by hyperthermia in Chinese hamster ovary cells: Role of antioxidant defenses. Arch Biochem Biophys 1999;363:283-95.

31. Siu LL, Moore MJ. Use of mesna to prevent ifosfamide-induced urotoxicity. Support Care Cancer 1998;6:144-54.

32. Alabbassi MG. The possible protective effects of zileuton against pulmonary fibrosis induced by amiodarone in male rats. J Nat Sci Res 2015;5 Suppl 2:88-92.

33. Fichtner-Feigl S, Strober W, Kawakami K, Puri RK, Kitani A. IL-13 signaling through the IL-13alpha2 receptor is involved in induction of TGF-beta1 production and fibrosis. Nat Med 2006;12:99-106.

34. Prechtl S, Roellinghoff M, Scheper R, Cole SP, Deeley RG, Lohoff M, et al. The multidrug resistance protein 1: A functionally important activation marker for murine th1 cells. J Immunol 2000;164:754-61.

35. Yang D, Elner SG, Bian ZM, Till GO, Petty HR, Elner VM, et al. Pro-inflammatory cytokines increase reactive oxygen species through mitochondria and NADPH oxidase in cultured RPE cells. Exp Eye Res 2007;85:462-72

36. Lo YY, Wong JM, Cruz TF. Reactive oxygen species mediate cytokine activation of c-jun NH2-terminal kinases. J Biol Chem 1996;271:15703-7.

37. Kolb M, Margetts PJ, Anthony DC, Pitossi F, Gauldie J. Transient expression of IL-1beta induces acute lung injury and chronic repair leading to pulmonary fibrosis. J Clin Invest 2001;107:1529-36.

38. Scheule RK, Perkins RC, Hamilton R, Holian A. Bleomycin stimulation of cytokine secretion by the human alveolar macrophage. Am J Physiol 1992;262:L386-91

39. Border WA, Noble NA. Transforming growth factor beta in tissue fibrosis. N Engl J Med 1994;331:1286-92.

40. Scotton CJ, Chambers RC. Molecular targets in pulmonary fibrosis: The myofibroblast in focus. Chest 2007;132:1311-21.

41. Ask K, Bonniaud P, Maass K, Eickelberg O, Margetts PJ, Warburton D, et al. Progressive pulmonary fibrosis is mediated by TGF-beta isoform 1 but not TGF-beta3. Int J Biochem Cell Biol 2008;40:484-95.

42. de Gouville AC, Huet S. Inhibition of ALK5 as a new approach to treat liver fibrotic diseases. Drug News Perspect 2006;19:85-90.

43. Ziesche R, Hofbauer E, Wittmann K, Petkov V, Block LH. A preliminary study of long-term treatment with interferon gamma- $1 \mathrm{~b}$ and low-dose prednisolone in patients with idiopathic pulmonary fibrosis. N Engl J Med 1999;341:1264-9.

44. Yoon JS, Chae MK, Jang SY, Lee SY, Lee EJ. Antifibrotic effects of quercetin in primary orbital fibroblasts and orbital fat tissue cultures of graves' orbitopathy. Invest Ophthalmol Vis Sci 2012;53:5921-9.

45. Rosas IO, Richards TJ, Konishi K, Zhang Y, Gibson K, Lokshin AE, et al. MMP1 and MMP7 as potential peripheral blood biomarkers in idiopathic pulmonary fibrosis. PLoS Med 2008;5:e93.

46. Pardo A, Selman M. Role of matrix metaloproteases in idiopathic pulmonary fibrosis. Fibrogenesis Tissue Repair 2012;5:S9.

47. Zuo F, Kaminski N, Eugui E, Allard J, Yakhini Z, Ben-Dor A, et al. Gene expression analysis reveals matrilysin as a key regulator of pulmonary fibrosis in mice and humans. Proc Natl Acad Sci U S A 2002;99:6292-7.

48. Punithavathi D, Venkatesan N, Babu M. Curcumin inhibition of bleomycin-induced pulmonary fibrosis in rats. $\mathrm{Br} \mathrm{J}$ Pharmacol 2000;131:169-72.

49. Arslan SO, Zerin M, Vural H, Coskun A. The effect of melatonin on bleomycin-induced pulmonary fibrosis in rats. J Pineal Res 2002;32:21-5

50. Hübner RH, Gitter W, El Mokhtari NE, Mathiak M, Both M, Bolte H, et al. Standardized quantification of pulmonary fibrosis in histological samples. Biotechniques 2008;44:507-11, 514-7.

51. Oury TD, Thakker K, Menache M, Chang LY, Crapo JD, Day BJ, et al. Attenuation of bleomycin-induced pulmonary fibrosis by a catalytic antioxidant metalloporphyrin. Am J Respir Cell Mol Biol 2001;25:164-9.

52. Daba MH, Abdel-Aziz AA, Moustafa AM, Al-Majed AA, A1Shabanah OA, El-Kashef HA, et al. Effects of L-carnitine and ginkgo biloba extract (EG b 761) in experimental bleomycin-induced lung fibrosis. Pharmacol Res 2002;45:461-7.

53. Zhao J, Shi W, Wang YL, Chen H, Bringas P Jr., Datto MB, et al. SMAD3 deficiency attenuates bleomycin-induced pulmonary fibrosis in mice. Am J Physiol Lung Cell Mol Physiol 2002;282:L585-93.

54. Pardo A, Ruiz V, Arreola JL, Ramírez R, Cisneros-Lira J, Gaxiola M, et al. Bleomycin-induced pulmonary fibrosis is attenuated in gammaglutamyl transpeptidase-deficient mice. Am J Respir Crit Care Med 2003;167:925-32.

55. Serrano-Mollar A, Closa D, Prats N, Blesa S, Martinez-Losa M, Cortijo J, et al. In vivo antioxidant treatment protects against bleomycininduced lung damage in rats. Br J Pharmacol 2003;138:1037-48.

56. Sushma RK, Sreedhara RP, Nayak JK, Hemalatha B, Keerthana P, Kumar MB. Biomechanical, biochemical and histological evidences for wound healing properties of Indian traditional medicines. Int J Pharm Pharm Sci 2015:7 Suppl 11:163-71

57. Iman HH, Mohamed AE, Ghada MA, Walaa GH. Protective effects of Zingiber officinale against carbon tetrachloride induced liver fibrosis. Int J Pharm Pharm Sci 2016;8 Suppl 3:377-81.

58. Massaous J, Hata A. TGF-beta signalling through the SMAD pathway. Trends Cell Biol 1997;7:187-92.

59. Heldin CH, Miyazono K, ten Dijke P. TGF-beta signalling from cell membrane to nucleus through SMAD proteins. Nature 1997;390:465-71. 